\title{
Sobre a mobilidade internacional de trabalhadores qualificados Brasil no foco do Quebec
}

\author{
Tatiana Accioly *
}

A mão de obra internacional sempre foi objeto de ampla importância nas discussões e práticas políticas internacionais. Em muitos momentos, no cenário mundial, a importação de braços para o trabalho era crucial para o desenvolvimento das economias em vias de expansão. Mas, apesar da grande importância desses "braços", as políticas de atração de imigrantes dos dois últimos séculos sempre foram, em alguma medida, seletivas. Os padrões de imigrante ideal foram mudando de acordo com a história, segundo as novas demandas da criação e ampliação do capital.

Durante as últimas décadas, as migrações internacionais têm adquirido novas características. A ampliação geográfica dos circuitos internacionais de migração e as políticas imigratórias que valorizam a disputa internacional por cérebros são um bom exemplo. A reestruturação produtiva, que vem se estendendo a várias partes do mundo, cria uma necessidade constante de trabalhadores com qualificações cada vez mais específicas. Para atender às suas necessidades de ampliação tecnológica, científica, produtiva, mercadológica, enfim, para garantir às economias mais desenvolvidas seu patamar de liderança e para alimentar o sonho das economias em desenvolvimento, o capital humano, representado pelo trabalhador qualificado, é disputado no cenário mundial e na política internacional.

O interesse estrangeiro pela mão de obra qualificada brasileira não é um assunto recorrente nos meios de comunicação e tampouco no meio acadêmico. Porém, ao analisar a divulgação sobre a emigração de brasileiros qualificados, nos

* Doutoranda do Instituto de Pesquisa e Planejamento Urbano e Regional - IPPUR/UFRJ. 
últimos anos, podemos encontrar uma curiosa matéria em página da internet. ${ }^{1}$ A matéria em questão, Quebec finca bandeira no Brasil - uma das poucas do gênero -, anuncia o estabelecimento do Escritório de Imigração do Quebec no país, numa elegante avenida da cidade de São Paulo.

O Escritório de Imigração do Quebec no Brasil tem como objetivo fundamental atrair o profissional qualificado brasileiro para trabalhar, residir e se naturalizar como cidadão canadense. Para tanto, bastam o interesse pelo projeto de emigrar para essa província canadense e a comprovação da aptidão linguística, em francês, da qualificação profissional e da capacidade para a assimilação dos chamados "Valores Comuns do Quebec" - tudo isso via uma interativa forma de análise, que inclui o preenchimento de um dossiê e algumas entrevistas. Em relação à qualificação profissional, o Escritório considera que o candidato ideal é aquele que possui o nível superior de ensino completo; porém, algumas qualificações de nível técnico são, também, aceitas no processo seletivo à emigração. Tal fato nos suscitou uma pergunta: o interesse do Quebec por profissionais qualificados brasileiros, evidenciado pelo estabelecimento de seu Escritório de Imigração no Brasil, insere os profissionais brasileiros no circuito internacional de mão de obra qualificada?

\section{Brasil - Quebec}

O Canadá é, atualmente, um dos poucos países do mundo a possuir políticas ativas para atração de imigrantes, sendo sem dúvida um dos que mais investem nesse campo. A imigração para o Quebec guarda particularidades em relação à imigração para outras províncias do Canadá. Desde 1990, a Constituição do país prevê a competência partilhada da imigração entre o governo federal e algumas províncias canadenses. Em virtude do acordo Canadá-Quebec sobre imigração, cabe ao governo do Quebec a seleção dos imigrantes da categoria independentes, que ainda estão em seus países de origem, como também a organização e realização da recepção e da integração linguística, cultural e econômica dos recém-chegados. Ao governo federal, cabe a admissão dos imigrantes e a responsabilidade sobre a presença de estrangeiros no país, assim como a concessão da cidadania canadense aos imigrantes estabilizados no Quebec por três anos ou mais. Com o intuito de expandir a sociedade francófona canadense, o Quebec possui escritórios de imigração espalhados nas mais diversas regiões do mundo, como, por exemplo, Magreb, Áustria, França, México, Síria e Hong Kong. Em abril de 2008, o governo do Quebec abriu um Escritório de Imigração na cidade de São Paulo, Brasil.

O Escritório de Imigração do Quebec no Brasil é multissetorial; ou seja, atende às estratégias de atração de trabalhadores qualificados brasileiros para a província, além de cuidar de interesses comerciais entre o Brasil e o Quebec. Sua diretora de imigração, Sra. Soraia Tandel, ${ }^{2}$ economista brasileira naturalizada canadense, é responsável por promover e administrar a emigração para o Quebec, 
não somente de indivíduos provenientes do Brasil, mas também da Argentina, Chile, Paraguai e Uruguai. Até 2008, o mesmo Escritório funcionava em Buenos Aires, e sua mudança para o Brasil se deve, entre outros possíveis motivos, a um estudo cujo objetivo era otimizar sua atuação nas áreas específicas de abrangência do Escritório na América Latina. Resultados indicaram que os brasileiros possuíam melhor formação, um perfil jovem já com experiência no mercado de trabalho em sua área de formação, bem como facilidade de comunicação em francês. Ademais, pelo que se pôde perceber da comunidade brasileira, ela não evidenciava tendências à formação de guetos étnicos, apresentando uma fácil assimilação cultural e participação social e econômica na vida quebequense.

Através de palestras ministradas por Soraia Tandel, em diversas cidades de importância econômica no Brasil, curiosos e pretendentes à imigração para o Quebec têm a oportunidade de assistir a uma série de propagandas informativas sobre o clima, as belezas naturais, a elevada qualidade de vida, o acesso à educação e à saúde pública de alta qualidade, e, sobretudo, o mercado de trabalho quebequense e os já mencionados "Valores Comuns do Quebec", pautados na igualdade, na democracia e na liberdade de expressão (CANADA, 2007). Muitas dúvidas da "plateia" são esclarecidas pela diretora, sendo mais recorrentes as que dizem respeito ao reconhecimento dos diplomas brasileiros no Quebec. Nesse sentido, é dito francamente ao público que poucos diplomas brasileiros são reconhecidos pelas Ordens Profissionais da província, embora o mercado de trabalho do Quebec esteja em expansão e necessite da mão de obra brasileira pela sua qualidade, eficiência e flexibilidade profissional. ${ }^{3}$ Aos interessados pela "vida no Quebec", faz-se um constante convite ao projeto de imigração, uma vez que as palestras acontecem periodicamente e são divulgadas ao público-alvo via internet, universidades e cursos de francês/inglês. Essas palestras já haviam sido assistidas, em dezembro de 2008, por cerca de quinze mil brasileiros.

Para participar do processo de emigração para o Quebec, sugere-se ao candidato a realização de um teste preliminar, disponível no site do Escritório na internet. ${ }^{4}$ Esse teste é composto de diversas etapas, nas quais o candidato responde basicamente a respeito de sua qualificação profissional, atuação no mercado de trabalho, experiência linguística e idade.

Desde 1967, o processo de seleção de imigrantes estabeleceu um sistema de pontos, que se tornou a principal ferramenta da política imigratória para assegurar que o fluxo de imigração pudesse satisfazer as necessidades econômicas do Canadá. A província do Quebec possui seu próprio sistema de pontos, que é diferente, em alguns aspectos, daquele do sistema federativo canadense. Ao simularmos uma grande sequência de testes de avaliação preliminar, verificamos que o jovem de trinta e cinco anos, com graduação universitária em uma ou mais áreas distintas, experiência de aproximadamente cinco anos no mercado de trabalho, e conhecimento de francês e inglês acima do nível considerado médio, é o tipo de candidato com mais chances de chegar a pontos suficientes para o êxito na obtenção do visto de imigração. Posteriormente, deve-se enviar uma 
série de documentos pessoais e comprobatórios profissionais, para que seja aberto pelo Escritório um dossiê de seleção para a imigração para o Quebec.

Um importante passo no processo de imigração é a entrevista conduzida em francês pela diretora Soraia Tandel e pelos demais responsáveis por essa etapa, no Escritório. Nessa entrevista, o foco principal é a verificação da abertura do candidato às culturas diversas que convivem no Quebec, como também a aptidão linguística para o francês e a flexibilidade profissional.

Através do informativo Apprendre le Québec, apresenta-se ao futuro imigrante uma espécie de "cartilha de assimilação" dos valores da sociedade quebequense, que, segundo um discurso idealista, prima pela democracia, pela expressão francesa e pluralista, e respeita os valores fundamentais da Carta de Direitos e Liberdades das Pessoas do Quebec, a qual concede a todos o direito à igualdade política, jurídica, econômica e social, e interdita todas as formas de discriminação (CANADA, 2005). Em relação à "verificação", feita pelo Escritório em entrevista com o candidato, quanto à sua tolerância às diferenças culturais e étnicas, bem como à suposta capacidade de assimilação dos valores multiculturais da sociedade quebequense, pode-se dizer - segundo depreendemos da fala da diretora - que os brasileiros possuem o perfil ideal de imigrante, uma vez que os "Valores Comuns do Quebec" seriam assimilados pelos brasileiros que se integram à sociedade quebequense, com facilidade e sem conflitos.

No ano de 2004, foi lançado o Plano de Ação para a Imigração, Integração e Relações Interculturais do Governo do Quebec, cujos objetivos são os de promover a compreensão e o respeito dos direitos e liberdades de todas as pessoas, assim como a igualdade e a sua participação na coletividade e no desenvolvimento da sociedade, além de facilitar o diálogo e o intercâmbio entre os quebequenses e os imigrantes, a fim de favorecer a abertura ao pluralismo e à aproximação cultural (BLOUIN, 2005). Um bom exemplo da política participativa é o Relatório BouchardTaylor, mais conhecido como Acordo de Acomodações Razoáveis, elaborado em 2008. Através de negociações com a sociedade local (nativos e imigrantes), chegou-se ao consenso de que alguns valores seriam comuns à sociedade, enquanto outros, particulares de algumas etnias, seriam vividos individualmente e respeitados socialmente, contanto que não agredissem os valores comuns da sociedade. Sendo assim, símbolos religiosos podem ser utilizados publicamente, assim como outras línguas podem ser faladas livremente entre as comunidades étnicas, desde que na vida pública se utilize o francês (LOPES, 2008).

Antes de sua emigração, esclarece-se ao candidato que ele deve buscar se integrar à sociedade, sendo eficiente e flexível no trabalho, para seu reconhecimento como bom funcionário. Dessa forma, ele estaria apto a obter promoções, estando aberto às diversas culturas existentes no Quebec e respeitando os "valores quebequenses".

Em relação à aptidão no idioma francês, Soraia Tandel esclarece a importância do conhecimento da língua, visto que o imigrante, chegando ao Quebec, viverá em uma sociedade francófona, utilizará serviços públicos informados em 
francês e participará de um mercado de trabalho que se comunica em francês. Segundo a diretora do Escritório de Imigração do Quebec, a questão da língua é fundamental para a assimilação da cultura quebequense e dos valores locais, bem como para a integração econômica do imigrante. Para tanto, o governo do Quebec oferece até mil horas de aulas de aprimoramento do francês, após a chegada do imigrante à província.

Em agosto de 1977, foi adotada pela Assembleia Nacional do Quebec a Carta da Língua Francesa, fruto de uma política governamental valorizando o emprego e a qualidade da língua francesa na vida pública dessa província (CANADA, 2003). Os objetivos fundamentais dessa Carta residem em garantir a perenidade e a expansão do idioma francês no Quebec. Fatores como a diminuição do peso demográfico dos francófonos no Canadá, a tendência presente na maioria dos imigrantes em matricular os filhos em escolas de língua inglesa - provocando diversas crises na rede de ensino quebequense -, e, ainda, a diminuição da taxa de natalidade na província fizeram com que o futuro demolinguístico dos francófonos no Quebec dependesse fortemente da imigração (BLOUIN, 2005, p. 5). A expansão da sociedade francófona não é o objetivo único das políticas de imigração do Quebec, mas o francês deve ser a língua da expansão econômica do Quebec e também o ponto de união das centenas de etnias que compõem essa sociedade, nos tempos atuais.

O governo do Quebec também fornece um auxílio na busca de empregos, com a análise do perfil profissional do imigrante a fim de adequá-lo às oportunidades de emprego vigentes no mercado de trabalho quebequense, e também auxilia na busca da complementação de estudos para atender às exigências das Ordens Profissionais, de modo que o indivíduo possa exercer sua profissão, caso ela seja regulamentada.

Segundo a Diretora do Escritório de Imigração do Quebec em São Paulo, apesar de o imigrante brasileiro chegar ainda desempregado ao Quebec, ele lá recebe auxílio do governo para encontrar um emprego, seja em sua especialização, ou em outras opções de emprego vigentes no mercado de trabalho local. A diretora também esclarece que não há a intenção de alocar brasileiros qualificados nos chamados subempregos, embora, em um primeiro momento, possa acontecer de o imigrante ser alocado em uma ocupação diferente daquela de sua formação profissional, não somente por conta das exigências das Ordens Profissionais, mas também devido às demandas do mercado de trabalho. Em relação aos casos em que o profissional já chega apto a exercer sua profissão, logo obtendo uma vaga em sua especialização, Tandel relata que pode ocorrer uma diferença salarial natural, decorrente da experiência do trabalhador no mercado de trabalho quebequense. A diretora enfatiza que todo o processo de seleção realizado pelo Escritório de Imigração do Quebec é transparente, no sentido de informar completamente as condições de emprego e salário, as profissões regulamentadas e a importância do papel do próprio imigrante no seu processo de integração social e econômica. 
A questão da flexibilidade profissional seria o ponto-chave do êxito econômico do imigrante brasileiro, uma vez que o diploma universitário, apesar de obrigatório para a obtenção de visto na província, não é, muitas vezes, reconhecido pelas Ordens Profissionais. Por isso, boa parte da mão de obra qualificada brasileira exerce funções diferentes ou abaixo de suas qualificações profissionais no mercado de trabalho do Quebec, levando-nos, assim, a considerar o fator da desvalorização da atuação profissional desses emigrantes. Vale ressaltar que as restrições aos diplomas universitários não são exclusivas aos brasileiros, mas a todos aqueles que possuem uma grade curricular diferente da canadense. Os emigrados que desejam exercer uma função em que tenham formação não reconhecida no Quebec devem fazer, portanto, um curso complementar para adequar suas qualificações às exigências da Ordem Profissional referente. Segundo Soraia Tandel, tal fato não se constitui como desmotivador para a maior parte dos brasileiros que buscam o Escritório de Imigração, pois os objetivos principais apresentados por esses interessados na emigração não passam necessariamente pelo "sonho" da realização profissional. Por outro lado, eles apontam como fatores motivadores a melhoria da qualidade de vida, graças ao nível próximo de zero de violência na província, e aos serviços de educação e saúde fornecidos pelo Estado, bem como uma melhoria na relação salário/custo de vida e o aumento do nível de consumo de bens materiais. As condições desejadas de salário e nível de vida são alcançadas, mesmo que o imigrante não esteja trabalhando em sua área de formação; daí a relevância do quesito flexibilidade profissional no processo de emigração - algo que acabou desafiando aquilo que, inicialmente, consideramos como a desvalorização profissional desse trabalhador.

\section{Rumo à sociedade de conhecimento?}

Sobre a política imigratória da província do Quebec, é manifesto o anseio pela expansão da sociedade francófona canadense, somado ao objetivo de formação e ampliação de uma sociedade de conhecimento de alto nível educacional e poder de consumo. Para tanto, a província teve de investir em políticas públicas de bem-estar social e em políticas imigratórias que satisfizessem aos quebequenses nativos e aos imigrantes.

Estabelecer um alto padrão de qualificação profissional no Quebec é o objetivo constante do governo provincial. Porém, faz-se necessário discutir as formas de gerenciamento da ocupação dos imigrantes no mercado de trabalho, segundo suas qualificações, bem como a integração social e econômica desses indivíduos na vida prática de uma sociedade formada por múltiplas etnicidades, e que busca uma identidade coerente com sua política multicultural. A integração econômica do imigrante está, segundo Reitz, diretamente relacionada à sua integração social. Da mesma forma, sua exclusão ou desvalorização econômica e ocupacional pode ser responsável pela geração de indisposições entre o imigrante não integrado e a sociedade local na qual está assentado (REITZ, 2004). A cidade 
de Montreal, por exemplo, apresenta a maior disparidade entre imigrantes e nativos, no que diz respeito à pobreza e à segregação social e espacial.

O argumento de que uma "guerra global por talentos" estaria emergindo justificou, a partir da década de 1990, a reformulação e a criação de políticas imigratórias específicas para a facilitação e o incentivo à contratação de trabalhadores estrangeiros qualificados, por parte de algumas das nações mais desenvolvidas do mundo (CORNELIUS, 2001). Tais medidas integravam os planos político-econômicos para a expansão e o fortalecimento de suas economias no mercado global.

Essas tendências apontam para um nível maior de exigência de formação e de atuação profissional do migrante em potencial: atrair "the brightest and the best brains of the world" ("os melhores e mais brilhantes cérebros do mundo") surge como reconhecido lema, que reflete uma competitividade mundial por talentos estrangeiros (CORNELIUS, 2001). Nesse contexto, chegamos ao perfil do imigrante brasileiro de alta qualificação, que demonstra aptidão linguística, facilidade de assimilação cultural, sendo, portanto, um candidato ideal às estratégias de captação de trabalhadores qualificados pela província do Quebec. Há de se ressaltar, por fim, que o Escritório de Imigração do Quebec estabeleceu-se no Brasil no mês de abril de 2008, sendo, por conseguinte, uma iniciativa recente, merecedora de investigações futuras de estudiosos interessados nas amplas possibilidades de desdobramentos da emigração brasileira qualificada para o Quebec.

\section{Notas}

1 - Acesso em 10 de setembro de 2008. Disponível em:

www.administradores.com.br/noticias/quebec_finca_bandeira_no_brasil/17100/

2 - Todas as declarações em nome de Soraia Tandel são provenientes de entrevista concedida à autora do presente artigo, no dia 17 de dezembro de 2008, no Escritório de Imigração do Quebec, São Paulo, SP. A diretora foi a única representante oficial do governo do Quebec a conceder entrevista.

3 - Em palestra assistida na PUC-RJ em março de 2009.

4 - http://www.immigration-quebec.gouv.qc.ca/placeauquebec/pt/

\section{Referências}

BARRETO, L. P. Considerações sobre a imigração no Brasil contemporâneo. In: CASTRO, M. G. e BERQUO, E. (orgs.). Migrações internacionais: contribuições para políticas. Brasília: Ministério do Planejamento, CNPD, 2001.

BLOUIN, S. Políticas e programas de imigração, integração e relações interculturais de Quebec. Quebec: Biblioteca da Assembléia Geral da COPA, 2005.

CANADA. Québec. Secrétariat à la politique linguistique. Viver em francês no Québec. Québec: Bibliothèque Nationale du Québec, 2003.

CANADA. Québec. Direction de la Recherche et d'Analyse Prospective. Bulletin statistique sur l'immigration permanente au Québec. Québec: Ministère de I'Immigration et des Communautés Culturelles, 2005. 
CANADA. Québec. Direction des Politiques et Programmes d'Intégration. Apprendre le Québec: Guide pour réussir mon intégration. Québec: Ministère de I'Immigration et des Communautés Culturelles, 2007.

CORNELIUS, W. et al. (org.). The international migration of the highly skilled. San Diego: University of California Press, 2001.

LOPES, L.C. Brasileiros de Montreal. Espéculo. Revista de estudios literarios. Madri: Universidad Complutense de Madrid, n.39, 2008.

Disponível em: < http://www.ucm.es/info/especulo/numero39/.html >.

QUEBEC finca bandeira no Brasil. Administradores - o portal da administração. Acesso em 10 de setembro de 2008. Disponível em:

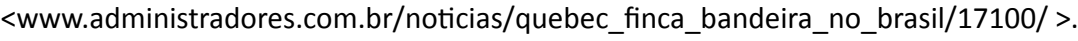

REITZ, J. Canada: Immigration and nation-building in the transition to knowledge economy. In: CORNELIUS, W.; TSUDA, T.; MARTIN, P.; HOLLIFIELD, J. Controlling immigration: a global perspective. California: Stanford University Press, 2004.

TANDEL, S. Entrevista com Soraia Tandel, realizada por Tatiana de A. Accioly. São Paulo, 17 de dezembro de 2008.

\title{
RESUMO
}

Atualmente, a importação de mão de obra estrangeira qualificada se mostra como estratégia de crescimento produtivo e mercadológico, tanto nos países mais desenvolvidos, como nos menos desenvolvidos. Seguindo tendências mundiais de captação de imigrantes qualificados para a formação da sonhada sociedade de conhecimento, o Quebec estabeleceu, em 2008, no Brasil, na cidade de São Paulo, o Escritório de Imigração do Quebec, tendo como objetivo fundamental atrair o profissional qualificado brasileiro para trabalhar, residir e se naturalizar como cidadão canadense. $O$ interesse do Quebec por profissionais qualificados brasileiros, bem como o estabelecimento de seu Escritório de Imigração no Brasil inserem os brasileiros no circuito internacional de mão de obra qualificada.

Palavras-chave: mão de obra qualificada; brasileiros; mercado de trabalho quebequense.

\begin{abstract}
Currently the importation of skilled foreign workers has proven to be a strategy for economic growth, both in the developed and in the less developed countries. Following such global tendencies of attracting qualified immigrants for the sought after establishment of a knowledge society, the Canadian province of Quebec set up in 2008 a Bureau of Immigration in the Brazilian megacity of São Paulo. The Bureau's main objective is to attract qualified Brazilian professionals to work, live and become Canadian citizens. Quebec's interest for Brazilian qualified workers and the establishment of its Bureau of Immigration in Brazil insert the country's nationals into the international skilled labor network.
\end{abstract}

Keywords: skilled workers; Brazilian people; labor market of Quebec. 